\title{
Cuba's National Health Sciences Prizes 2007
}

\section{By Gloria Giraldo, MPH}

In December 2007, Cuba's National Health Science Prizes were awarded for outstanding contributions to basic science, clinical medicine, and population health. The prizes, first bestowed in 1976, are sponsored by Cuba's Ministry of Public Health and the National Council of Scientific Societies. Works are selected based on excellence, scientific rigor, and relevance. In 2007, one Grand Prize, 13 additional prizes, and 11 special mentions were awarded from among 244 entries forwarded from the provincial level.

\section{National Health Sciences Prizes: Selection Process}

- Health professionals from all fields submit their work in Cuba's 169 municipalities. Provincial juries select the best entries from Cuba's 14 provinces. These are forwarded to the National Jury, which then narrows the selection. Finalists are put to an additional test by two outside experts. Dr Wilfredo Torres Yríbar, Jury Chair, explains: "The National Jury studies these expert opinions and the provincial judges' recommendations to arrive at a final decision."

- Prizes are awarded in: basic research, applied research, technological innovation, medical education, clinical reviews, published articles, books, doctoral dissertations and master's degree theses. Two to nine prizes are awarded per category, and one Grand Prize.

- For a complete list, in Spanish, of the 2007 prizewinners, consult: http://www.sld.cu/temas.php?idv=17924.

MEDICC Review spoke with the Grand Prize winner, as well as awardees in the categories of applied research, basic science, and published scientific article.

\section{Grand Prize in Health Sciences 2007}

Isle of Youth community-based epidemiological study of chronic kidney disease, cardio-cerebral vascular disease, hypertension and diabetes mellitus (ISYS). (Estudio Epidemiológico en la Comunidad de Enfermedad Renal Crónica, Enfermedad Cardiocerebrovascular, Hipertensión Arterial y Diabetes Mellitus. Isla de la Juventud. ISYS.)

Authors: Raúl Herrera Valdés, MD, PhD, DrSc, Miguel Almaguer López, MD, José Chipi Cabrera, MD, Xidix Toirac Cabrera, MD, Osvaldo Castellanos Rabana, MD, et al.

Institution: Institute of Nephrology, Havana; Isle of Youth Health Department.

The Grand Prize is awarded to exceptional work in any field. This year's prize went to the Institute of Nephrology's community-based study ISYS, which is Cuba and the world's first study in total geographic population of chronic kidney disease (CKD) and related chronic vascular diseases. "Studying the entire population gives unique value to the results," lead author Dr Raúl Herrera told MEDICC Review. ISYS involves inhabitants of the island municipality

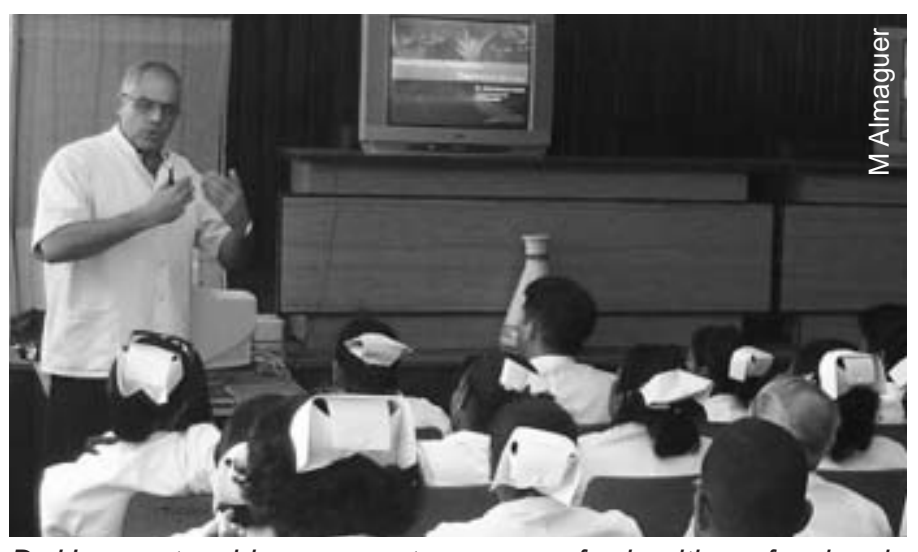

Dr Herrera teaching preparatory course for health professionals participating in ISYS

of the Isle of Youth, $120 \mathrm{~km}$ south of the Cuban mainland. Previous informed consent, $97 \%$ of the Isle's population is participating in the longitudinal study, over 77,000 persons from newborn infants to the oldest residents.

The Grand Prize was awarded to ISYS based on the results of Phase 1, which used interviews, physical examinations, and urine and blood tests to identify risk factors associated with CKD, cardio-cerebral vascular disease and diabetes mellitus; and to determine prevalence of each of these in total population. "In essence," explained Dr Herrera, "ISYS is using CKD as a tracer disease for other chronic conditions, by concentrating on markers for early detection of the vascular damage they have in common."

One particularity of ISYS has been the mobilization of human resources: initial data collection was carried out by over 100 family doctors and nearly 200 family nurses who staff the primary care network of doctor-nurse offices throughout the Isle of Youth.

These health professionals - as well as participating laboratory, informatics, hospital and clinic staff - received a certificate course to prepare them for their roles in ISYS.

Basing the study in the primary care network has facilitated immediate post-Phase 1 intervention in population and individual health, carried out by the neighborhood-based family doctor-nurse teams. This, according to Dr Herrera, is part of the Phase 2 strategy now beginning. "We're now working on individual case studies among persons who tested positive for vascular damage and those diagnosed with a chronic vascular disease. This involves a strong emphasis on secondary prevention to eliminate or control risk factors, wherever possible, and reverse, halt or slow progression of their condition," he said.

ISYS is expected to yield results that will influence the way prevention and treatment are managed on the Isle and eventually in Cuba as a whole, and also help determine where resources should be deployed. "The study is multi-faceted, and its results are already guiding changes in the next phases, For example, based on Phase 1, we're starting active and continuous epidemiologi- 
cal surveillance, incorporating the cases found through the initial screening," explained Dr Herrera. He notes that active surveillance should aid in developing a more holistic approach for education, health promotion, treatment and secondary prevention. Beyond the health system, he says, the findings indicate a need for intersectorial actions involving schools, physical education programs, the food industry, and the agricultural sector, among others.

New lines of research are also emerging based on the early results. "For example," says Dr Herrera, "we will now be able to study sub-populations of diabetics with CKD, and then be able to study other co-morbidities such as obesity, hypertension and cardiovascular disease (CVD)." (See: Herrera R, et al. Obesity and Chronic Kidney Disease (CKD), Hypertension and Diabetes Mellitus. ISYS Study. Cuba. In this issue, Eds.)

Implications of ISYS findings may reach well beyond Cuba. The Isle of Youth is both geographically and demographically similar to many other Caribbean islands. Additionally, Cuba's health indicators are comparable to those in industrialized countries, although its socioeconomic status describes it as a developing country, making comparisons with studies from both contexts feasible.

(See also: Almaguer M et al. Design \& Methodology of the Isle of Youth Community-Based Epidemiological Study of CKD, Cardiocerebral Vascular Disease, Hypertension, and Diabetes Mellitus (ISYS). MEDICC Review 2007;9(1): 23-30.)

\section{Basic Science Research Category, Prize Winner} Universality of basolateral amygdala stimulation effects on neuroplasticity processes. (Universalidad de los efectos de la estimulación de la amígdala basolateral sobre los procesos de neuroplasticidad.)

Authors: Jorge A. Bergado Rosado, PhD, Yeneissy Rojas, MD, Vladimir Capdevila, MD, William Almaguer Melián, PhD, et al.. Institution: International Center for Neurological Restoration (CIREN), Havana.

For the last 10 years, Dr Bergado and his team have worked with a group from Magdeburg, Germany, to study basic physiological mechanisms that may influence neural plasticity. The relevance of their work lies in searching for underlying mechanisms to stimulate neural plasticity in patients with injured central nervous system or in treatment of chronic neurological diseases.

Neural plasticity refers to the nervous system's capacity to change its basic structure and even function, in response to environment. Neural plasticity describes the process when, for example, a person learns something new or acquires a new skill, and functional modifications in synapses occur or new synapses are formed. This phenomenon has been described since 1973, prompting more intensive study in recent decades.

The CIREN team studies how cognitive and motivational processes may interact and modify the course and intensity of neuroplastic changes at synaptic levels. They have been seeking structures within the nervous system that could mediate this interaction between cognitive and neuroplastic processes. Dr Bergado told MEDICC Review that early on they suspected that the amygdala in the limbic system would play a role in this mediation, given the amygdala's relationship to emotional response.

Dr Bergado's team and German colleagues studied healthy rodents, showing that electrical stimulation to the amygdala in specific patterns produced an extension of the neuroplastic process in the hippocampus, a nearby limbic structure involved in memory functions. They also showed that inactivation of the amygdala affected neuroplasticity processes.

To bring this knowledge closer to possible application in injured patients, they studied a broader set of conditions including the effects of amygdala stimulation on rodents with lesions, and the effects of amygdala stimulation on other brain structures. The National Health Sciences Prize recognized their latest research reflected in two main studies. The first showed that stimulation of the amygdala in animals with lesions markedly affecting their cognitive capabilities resulted in recovery of function to a level comparable to healthy animals.[1] In the second study, they explored effects of amygdala electrical stimulation on memory processes, such as the acquisition of a new motor skill, which showed that amygdala stimulation accelerated skill acquisition time. Since this type of skill is found in the cerebral cortex, the results indicate that stimulation of the amygdala can also affect cortical plasticity. Jointly, these results suggest that the amygdala may influence neural plasticity in many different brain structures and processes.[2]

"To an important degree, this line of research is at the conceptual core of our institution, which is dedicated to neurological restoration through intensive rehabilitative processes," explains Dr Bergado. CIREN's treatment model is anchored by a team of physical, occupational, and rehabilitation therapists working under the direction of a neurologist. Therapy is intensive-seven hours a day, tailored to each patient. "Our work leads us to think that amygdala stimulation may be a complementary tool to stimulate neural plasticity in the injured central nervous system," notes $\mathrm{Dr}$ Bergado. "This is the beginning of a journey to improve rehabilitation outcomes. But there is still much work to be done."

\section{Applied Research Category, Special Mention}

Hypertension in Cienfuegos, 2001-2002: A public health perspective on assessment of sociodemographic factors associated with blood pressure levels, and on prevalence and rates of hypertension control in the population. (Hipertensión Arterial en Cienfuegos, 2001-2002. Una perspectiva de salud pública en la valoración sociodemográfica de los niveles de presión arterial, la prevalencia y las tasas de control poblacional de la enfermedad.)

Authors: Pedro Ordúñez García, MD, PhD, Luis C. Silva Ayçaguer, $\mathrm{PhD}$, Alfredo D. Espinosa Brito, MD, PhD, José Luis Bernal Muñoz, MD and Richard S. Cooper, MD.

Institution: Gustavo Aldereguía Lima Provincial Teaching Hospital, Cienfuegos.

For several years, Dr Ordúñez and his colleagues have studied chronic disease in Cienfuegos, a province $250 \mathrm{~km}$ east of $\mathrm{Ha}-$ vana. This research falls within the Pan American Health Organization (PAHO) initiative for prevention and control of chronic diseases and its CARMEN (Multiple Risk Factor Interventions to Reduce Noncommunicable Diseases) network. The team, which 
includes Chicago scientist Dr Richard Cooper[3] has published widely on its studies of high blood pressure (HBP) as a public health problem in Cienfuegos. One of the group's articles was also awarded a National Health Sciences Prize for 2007.[4]

Dr Ordúñez explains that hypertension has presented technical and organizational challenges for the Cienfuegos health system due to high prevalence (20\%), and the broad susceptibility of all population groups, particularly as they age. He adds, "Higher prevalence signifies higher demand for services, more and larger variety of medications, higher risk of complications, and greater complexities in disease management for both patients and health personnel." However, the Cienfuegos' study concludes that even in a low-resource setting, hypertension control can be achieved within a universal health system that is free to patients, that offers broad coverage and essential medications at affordable prices.

Comparing HBP prevalence among various demographic groups, the Cuban research findings differ with those from similar US studies. In Cienfuegos, the team found relatively narrow HBP rate differences between persons who identified as black or white. For men and women of the same age, the ratio of black-to-white HBP prevalence was 1.64:1; while in the US, the ratio was 2.4:1. "High public awareness of HBP, as well as high treatment levels and notable disease control in the Cienfuegos population of all racial identities, may reflect a high level of inclusion in the health system," Dr Ordúñez told MEDICC Review.

Dr Ordúñez says gender patterns of hypertension were among the study's most interesting findings. Data analysis revealed that although blood pressure differences between black and white women were modest ( $3 \mathrm{mmHg}$ systolic and $1 \mathrm{mmHg}$ diastolic), the HBP prevalence differential was substantial: HBP was $24 \%$ in black women, and only $15 \%$ in white women. Yet, prevalence in men was $23 \%$ for both groups. These results led the team to believe that the socially mediated processes than influence HBP rates follow gender-specific pathways in this population.[4,5]

Among the steps suggested by the Cienfuegos team to improve HBP control is structuring a national epidemiological surveillance system for HBP and other cardiovascular disease risk factors-a recommendation similar to that generated by the Grand Prize study. In this context, Dr Ordúñez emphasized: "We must reinforce a public health perspective in designing health policies and programs to effectively address identified sociodemographic differences." He stressed the importance of re-designing services to more effectively reach young and middle-aged people.
Dr Ordúñez believes that the primary care level is an ideal scenario for HBP prevention and control, and that it "should continue to be the pivotal point in the unfolding integrated strategies". He says that HBP should occupy a strategic place in national health policy to improve overall health, addressing certain medular issues: production and access to healthy foods; spaces and resources for generalized practice of sports and other physical activity; and enforcement, expansion and coherence of tobacco use control.

(See also: Giraldo, G. Interview. Pedro Ordúñez, MD: Director, Gustavo Aldereguía Lima Provincial Teaching Hospital, Cienfuegos. MEDICC Review. 2008;10(1):15-17.)

\section{Scientific Article Category, Prize Winner \\ Drug-resistant tuberculosis in Cuba. Results of the three global projects, published in Tuberculosis.[6]}

Authors: Ernesto Montoro Cardoso, MD, PhD, Dihadenys Lemus, PhD, Miguel Echemendía, Luisa Armas, MD, Edilberto González Ochoa, MD, PhD, María J. Llanes, MD, and José A. Valdivia, PhD.

Institution: Pedro Kourí Institute of Tropical Medicine, Havana.

Dr Ernesto Montoro provided MEDICC Review with background on his paper, explaining that in 2006, "Cuba's total tuberculosis (TB) rate was 6.2 per 100,000 population (approximately 700 cases), reflecting the successful TB control program established in 1963." Since 1975, the national TB reference laboratory tests $100 \%$ of cultures from symptomatic patients nationwide, including determination of drug susceptibility.

The prize-winning article describes TB multi-drug resistant (MDR) patterns of $M$. tuberculosis strains isolated in Cuba from new patients and patients with a history of TB drug treatment. The data are derived from three global projects of TB surveillance from 1997 to 2004, organized by the World Health Organization (WHO) and the International Union against Tuberculosis and Lung Diseases. Cuba was the only Latin American country to participate.

For the first (1997), second (2000) and third (2004) global studies, results in Cuba showed resistance in new cases at $8.3 \%, 4.6 \%$ and $5.0 \%$, and MDR at $0.7 \%, 0 \%$ and $0.3 \%$, respectively. The declining TB drug resistance in Cuba corresponds to high cure rates among patients and low rates of treatment failure and dropout. Results also showed low circulation of MDR-M. tuberculosis strains, the lowest in the Americas.[7] Dr Montoro says these results support prospects for beginning TB elimination in Cuba

\section{References \& Notes}

1. Almaguer W, Capdevila V, Ramírez M, Vallejo A, Rosillo, J and Bergado JA. Post-training stimulation of the basolateral amygdala improves spatial learning in rats with lesion of the fimbria-fornix. Restor Neurol Neurosci. 2005;23:4350.

2. Bergado JA, Rojas Y, Capdevila V, González O, Almaguer-Melian W. Stimulation of the basolateral amygdala improves the acquisition of a motor skill. Restor Neurol Neurosci. 2006;24(2):115-21.

3. Richard Cooper is the Anthony B. Traub Professor and Chairman, Department of Epidemiology and Preventive Medicine, Loyola University Stritch School of Medicine, Chicago.
4. Ordúñez-García P, Muñoz JLB, Pedraza D, et al. Success in control of hypertension in a low-resource setting: the Cuban experience. J Hypertens. 2006;24(5):845-9.

5. Ordúñez P, Muñoz JLB, Espinoza-Brito A, Silva LC, Cooper RS. Ethnicity, education and blood pressure in Cuba. Am J Epidemiol. 2005;162(1):49-56.

6. Montoro E, Lemus D, Echemendía M, Armas L, González-Ochoa E, Llanes MJ, Valdivia JA. Drug-resistant tuberculosis in Cuba. Results of the three global projects. Tuberculosis. 2006;86:319-23.

7. Zignol M, Hosseini MS, Wright A, et al. Global incidence of multidrugresistant tuberculosis. J Infect Dis. 2006;194:479-85. 